\title{
Pengaruh Dua Macam Perlakuan Mikroorganisme terhadap Kemudahan Degradasi Poliuretan Hasil Sintesis dari Monomer Polietilen Glikol Berat Molekul 400 dengan Metilen-4,4'- difenildiisosianat
}

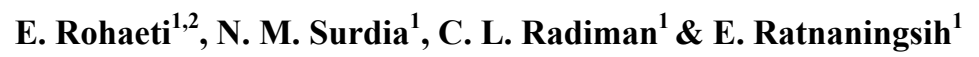 \\ ${ }^{1}$ Departemen Kimia FMIPA Institut Teknologi Bandung, \\ Jl. Ganesha 10 Bandung 40132, Telp. (022)2502103, \\ E-mail: s398eli@mail.chem.itb.ac.id \\ 2 Jurdik Kimia FMIPA Universitas Negeri Yogyakarta, Kampus Karangmalang \\ Yogyakarta 55281, Telp. (0274)586168 Ext. 215
}

Sari. Telah dilakukan penelitian tentang degradasi lembaran poliuretan menggunakan dua macam perlakuan mikroorganisme. Pada penelitian ini, poliuretan diperoleh dari reaksi antara polietilen glikol berat molekul 400 dengan metilen-4,4'-difenildiisosianat pada temperatur kamar yang diikuti dengan perlakuan tekan panas pada temperatur $180^{\circ} \mathrm{C}$. Karakterisasi poliuretan didasarkan pada analisis gugus fungsi dengan teknik spektrofotometri Fourier Transform Infra Red dan sifat termal dengan menggunakan Differential Thermal Analysis, serta sifat fisik dengan menggunakan X-Ray Diffraction. Degradasi poliuretan dilakukan dengan dua perlakuan menggunakan lumpur aktif dibandingkan dengan penggunaan Pseudomonas aeruginosa dalam media Luria Bertani cair pada temperatur $37^{\circ} \mathrm{C}$. Variasi waktu inkubasi berturut-turut adalah $5,10,15,20,25$, dan 30 hari, dengan penggantian media tiap 5 hari. Hasil penelitian menunjukkan bahwa poliuretan dapat terbiodegradasi, meskipun dengan laju degradasi yang berbeda. Kehilangan berat poliuretan yang diinkubasi dalam lumpur aktif lebih tinggi dibandingkan dengan dalam Pseudomonas aeruginosa. Dengan demikian perlakuan dengan lumpur aktif lebih efektif dibandingkan perlakuan dengan Pseudomonas aeruginosa dalam mendegradasi poliuretan. Hasil identifikasi dengan X-Ray Diffraction menunjukkan bahwa degradasi menurunkan derajat kristalinitas poliuretan. Spektrum Fourier Transform Infra Red sesudah proses degradasi menunjukkan hilangnya puncak khas gugus uretan dari poliuretan. Untuk setiap variasi waktu inkubasi menunjukkan bahwa produk poliuretan memiliki kehilangan berat paling tinggi pada waktu inkubasi 5 hari.

Kata kunci: poliuretan, Pseudomonas aeruginosa, degradasi, kehilangan berat, lumpur aktif.

Abstract. Degradation of polyurethane sheets using two types of microorganism treatment has been carried out. In this research, the polyurethane sheets were prepared by polyethylene glycol with a molecular weight of 400 and methylene4,4'-diphenyldiisocyanate at room temperature, followed by heat-pressed at 
temperature of $180^{\circ} \mathrm{C}$. Characterization of polyurethane sheets was based on functional groups using Fourier Transform Infra Red spectrophotometry and thermal properties using Differential Thermal Analysis, and also for physical properties using X-Ray Diffraction. Degradation treatment was carried out by exposing polyurethane to activated sludge and compared to Pseudomonas aeruginosa in a Luria Bertani liquid media at $37^{\circ} \mathrm{C}$. The variation of incubation time was $5,10,15,20,25$, and 30 days, respectively with changes of media every 5 days. After degradation, weight loss of polyurethane sheets was determined. The result showed that polyurethane was biodegradable, although at different degradation rate. Weight loss of polyurethanes by activated sludge was higher than by Pseudomonas aeruginosa. Thus, activated sludge was more effective than Pseudomonas aeruginosa in degradating polyurethane. Identification with X-Ray Diffraction showed that degradation decreased the degree of crystallinity of the polyurethane material. Fourier Transform Infra Red spectra after degradation showed that the specific peak for the urethane group disappeared. Variation of the incubation time showed that the polyurethane product had the highest weight loss during the first five days.

Keywords: polyurethane, Pseudomonas aeruginosa, degradation, weight loss, activated sludge.

\section{$1 \quad$ Pendahuluan}

Poliuretan merupakan bahan polimer yang mengandung gugus fungsi uretan (-NHCOO-) dalam rantai utamanya [1]. Gugus uretan terbentuk dari reaksi antara gugus isosianat dengan gugus hidroksil, seperti nampak dalam persamaan reaksi berikut:

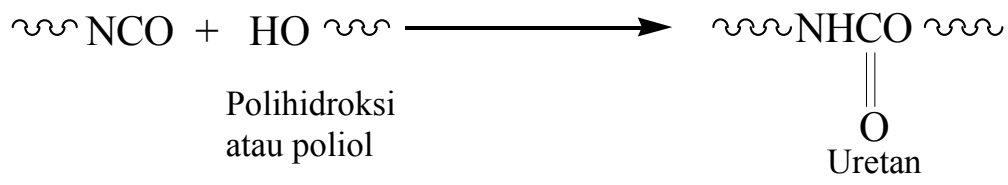

Di bidang otomotif, poliuretan dapat dijumpai sebagai komponen kendaraan yang meliputi bagian eksterior dan interior misalnya bumper, panel-panel body, tempat duduk, dan lain-lain [2,3]. Di bidang kedokteran, poliuretan digunakan sebagai bahan pelindung muka, kantung darah, dan tabung [3]. Selain itu poliuretan telah digunakan pula untuk furniture, bangunan dan konstruksi, insulasi tank dan pipa, pabrik pelapis, alat-alat olahraga, serta sebagai bahan pembungkus $[2,4]$. Nampaknya pemakaian poliuretan akan terus meningkat mengingat keunggulan sifatnya dan pemakaiannya praktis.

Masalah yang timbul kemudian akibat peningkatan penggunaan poliuretan adalah makin bertumpuknya limbah poliuretan. Hal ini apabila tidak segera ditanggulangi akan membahayakan kelestarian lingkungan hidup. Cara 
penanggulangan yang dianggap paling bersahabat dengan lingkungan dan tidak menimbulkan masalah baru adalah dengan proses biodegradasi.

Penelitian untuk mendapatkan poliuretan yang mudah terdegradasi sudah mulai dilakukan. Hasilnya menunjukkan bahwa melalui reaksi selulosa dengan diisosianat tanpa penambahan dan dengan penambahan polipropilen glikol diperoleh kopolimer blok selulosa yang dapat terbiodegradasi [5]. Kemudian telah disintesis poliuretan yang dapat terbiodegradasi menggunakan komonomer berupa lignoselulosa. Berbagai sumber tumbuhan seperti lignin kraft, kopi, sakarida dapat dibuat poliuretan lewat pencampuran dengan polietilen glikol atau polipropilen glikol dan direaksikan dengan difenilmetan diisosianat [6]. Dengan cara mereaksikan poli-D,L-asam laktat dengan pMDI (polimetilen polifenil poliisosianat) telah berhasil disintesis poliuretan yang dapat terbiodegradasi pula [7].

Dengan meninjau hasil-hasil penelitian yang telah dilakukan sebelumnya maka pada penelitian ini telah dilakukan degradasi poliuretan hasil sintesis dari polietilen glikol berat molekul 400 (PEG400) dengan metilen-4,4'difenildiisosianat (MDI) menggunakan lumpur aktif dan Pseudomonas aeruginosa. Tujuan dari penelitian ini adalah untuk mengetahui pengaruh penggunaan mikroorganisme terhadap kemudahan degradasi poliuretan hasil sintesis dari PEG400 dan MDI.

\section{Bahan dan Metode}

\subsection{Bahan}

Bahan-bahan yang digunakan dalam sintesis poliuretan dan biodegradasinya, yaitu:

i. MDI berupa cairan kental berwarna coklat dengan rumus struktur sebagai berikut :

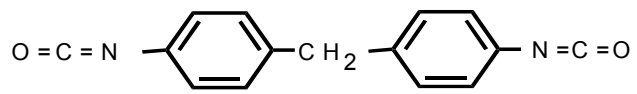

ii. PEG400 berupa cairan kental tak berwarna dengan rumus struktur sebagai berikut :

$\mathrm{HO}-\left(\mathrm{CH}_{2} \mathrm{CH}_{2} \mathrm{O}\right)_{n}-\mathrm{H}$

iii. Kultur campuran (mixed culture) dari lumpur aktif berupa gumpalan (flok) dari berbagai macam mikroorganisme yang diperoleh dari laboratorium Bioteknologi Lingkungan PPAU-ITB

iv. Kultur murni (pure culture) Pseudomonas aeruginosa

v. Etanol $70 \%$ untuk mensterilkan poliuretan yang akan dibiodegradasi

vi. Media Luria Bertani (LB) cair sebagai media biodegradasi 


\subsection{Metode}

\subsubsection{Reaksi Polimerisasi Pembentukan Poliuretan dan Karakterisasinya}

Pada tahap ini dilakukan reaksi polimerisasi pada temperatur kamar dengan perbandingan $\mathrm{NCO} / \mathrm{OH}$ adalah 1,17. PEG400 direaksikan dengan MDI pada temperatur kamar dan diperolehlah poliuretan yang precured. Poliuretan precured ini selanjutnya ditekan panas sehingga diperoleh poliuretan bentuk lembaran (film) ukuran $10 \times 10 \mathrm{~cm}^{2}$ dengan ketebalan $0,8-1,0 \mathrm{~mm}$. Sampel poliuretan dimasukkan ke dalam vacuum oven sebelum dikarakterisasi.

Selanjutnya dilakukan karakterisasi poliuretan dengan teknik spektrofotometri Fourier Transform Infra Red (FTIR) untuk melihat puncak serapan dan uji sifat termal diukur dengan menggunakan teknik Differential Thermal Analysis (DTA), General V4. 1C Du Pont 2000.

\subsubsection{Biodegradasi Poliuretan dalam Medium LB Cair dan Karakterisasinya}

Dalam ruang laminar flow, $5 \mathrm{~mL}$ cairan yang berisi satu ose (tusukan) kultur murni Pseudomonas aeruginosa dan kultur campuran berbagai mikroorganisme dari lumpur aktif masing-masing dituang ke dalam erlenmeyer yang berisi LB cair. Poliuretan steril dengan ukuran $1 \mathrm{x} 1 \mathrm{~cm}^{2}$ dimasukkan ke dalam erlenmeyer yang telah berisi media dan mikroorganisme. Kemudian erlenmeyer disimpan pada shaker liquid incubator pada temperatur $37^{\circ} \mathrm{C}$ selama $5,10,15$, 20, 25, dan 30 hari. Setiap proses biodegradasi dilakukan sebanyak lima kali ulangan. Proses biodegradasi dihentikan dengan mencelupkan poliuretan ke dalam etanol $70 \%$. Kemudian dicuci beberapa kali dengan aquadest, dan poliuretan siap dikarakterisasi. Selanjutnya dilakukan karakterisasi untuk setiap produk polimer hasil biodegradasi dengan penentuan kehilangan berat, teknik spektrofotometri FTIR untuk melihat puncak serapan, dan uji derajat kristalinitas dengan teknik X-Ray Diffraction (XRD).

\section{$3 \quad$ Hasil dan Diskusi}

\subsection{Hasil Reaksi Pembentukan Poliuretan dan Karakterisasinya}

\subsubsection{Spektrum FTIR}

Hasil karakterisasi terhadap poliuretan hasil sintesis dengan teknik spektroskopi FTIR menunjukkan pita serapan pada $3330 \mathrm{~cm}^{-1}$ yang merupakan daerah ulur $\mathrm{N}-\mathrm{H}, 1720 \mathrm{~cm}^{-1}$ merupakan daerah serapan ulur $\mathrm{C}=\mathrm{O}$ bebas, $1700 \mathrm{~cm}^{-1}$ merupakan daerah serapan ulur $\mathrm{C}=\mathrm{O}$ yang berikatan hidrogen, $1541 \mathrm{~cm}^{-1}$ merupakan daerah serapan deformasi $\mathrm{N}-\mathrm{H}, 1400 \mathrm{~cm}^{-1}$ merupakan daerah 
serapan C-N-C, dan $\sim 1100 \mathrm{~cm}^{-1}$ yang merupakan daerah serapan ulur C-O. Pembandingan spektrum FTIR poliuretan hasil sintesis dengan data referensi menunjukkan pita-pita serapan pada daerah yang hampir sama terutama pada daerah pita serapan karakteristik. Pada Gambar 1 tampak hasil spektrum FTIR poliuretan yang berasal dari PEG400-MDI. Berdasarkan hasil perhitungan besarnya indeks ikatan hidrogen (HBI) menunjukkan bahwa poliuretan memiliki HBI sebesar 0,63, ini mengindikasikan bahwa dalam molekul poliuretan tersebut terdapat ikatan hidrogen sebagai gaya sekunder yang mengikat antar atom dalam material polimer .

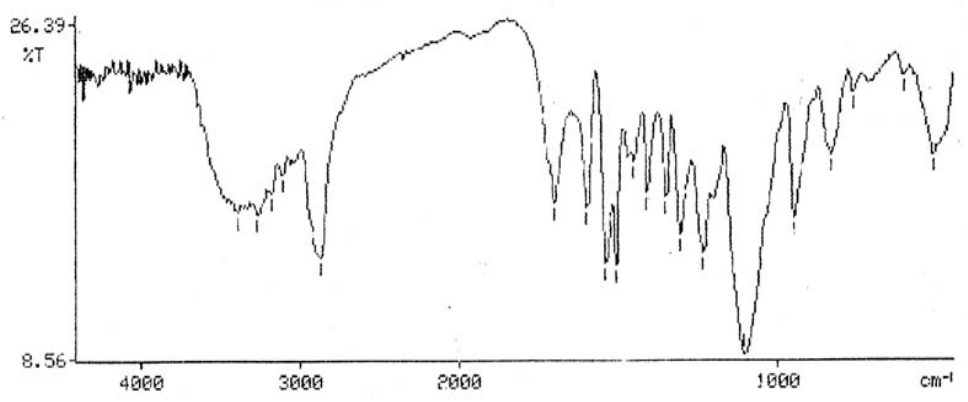

Gambar 1 Spektrum FTIR Poliuretan Hasil Sintesis dari PEG400 - MDI.

Menurut Huang [8], nilai HBI dapat menunjukkan terjadinya antaraksi intermolekuler antara hard segment-hard segment dalam daerah hard segment untuk bergabung daripada terdispersinya hard segment dalam daerah soft segment.

\subsubsection{Sifat Termal}

Berdasarkan analisis kurva hasil pengukuran dengan teknik DTA diperoleh data temperatur transisi gelas poliuretan, yaitu $89,58^{\circ} \mathrm{C}$ dan temperatur leleh poliuretan, yaitu $444,87^{\circ} \mathrm{C}$. Nilai temperatur transisi gelas poliuretan hasil sintesis menunjukkan nilai hampir sama dengan penelitian sebelumnya [1], sedangkan nilai temperatur leleh poliuretan hasil sintesis jauh lebih tinggi dibandingkan dengan penelitian sebelumnya [1].

\subsubsection{Biodegradasi Poliuretan dalam Medium LB Cair dan Karakterisasinya}

Dari hasil pengamatan menggunakan foto makroskopik menunjukkan bahwa masing-masing poliuretan yang diinkubasi dalam media LB cair menggunakan lumpur aktif dan Pseudomonas aeruginosa ditumbuhi mikroorganisme yang jumlahnya semakin bertambah dengan bertambahnya waktu inkubasi dan 
ditandai dengan semakin keruhnya media LB yang digunakan dalam proses biodegradasi.

Untuk menguji kemudahan degradasi poliuretan oleh mikroorganisme dapat dilakukan dengan cara menghitung persen kehilangan berat. Semakin tinggi persen kehilangan berat berarti semakin mudah poliuretan terbiodegradasi. Pada Tabel 1 nampak data kehilangan berat rata-rata poliuretan yang masing-masing diinkubasi dalam lumpur aktif dan Pseudomonas aeruginosa. Kehilangan berat total poliuretan yang diinkubasi dalam lumpur aktif sebesar 7,520\%, sedangkan poliuretan yang diinkubasi dalam Pseudomonas aeruginosa kehilangan berat total sebesar $4,745 \%$. Kehilangan berat total poliuretan yang diinkubasi dalam lumpur aktif lebih tinggi dibandingkan dalam Pseudomonas aeruginosa. Dengan demikian lumpur aktif lebih efektif dalam mendegradasi poliuretan. Hal ini dapat disebabkan karena jenis bakteri yang terdapat dalam lumpur aktif sangat bervariasi, sebagaimana literatur menunjukkan bahwa jenis bakteri dari genus Pseudomonas, Zooglea, Bacillus, Athrobacter, Microthrix, Nacordia, Acinetobacter, Nitrobacter, Achromobacter, dan Nitrosomonas dapat ditemui dalam lumpur aktif. Dengan bervariasinya jenis bakteri dalam lumpur aktif, maka ketika satu jenis bakteri mati karena kehabisan nutrisi maka bakteri jenis lain dapat menggantikannya demikian seterusnya sehingga poliuretan yang diinkubasi dalam lumpur aktif lebih mudah terbiodegradasi daripada poliuretan yang diinkubasi dalam Pseudomonas aeruginosa.

\begin{tabular}{|c|c|c|}
\hline \multirow{2}{*}{$\begin{array}{c}\text { Lama inkubasi } \\
\text { (hari) }\end{array}$} & \multicolumn{2}{|c|}{ Kehilangan berat (\%) } \\
\cline { 2 - 3 } & Pseudomonas aeruginosa & Lumpur aktif \\
\hline & 1,459 & 4,468 \\
\hline 10 & 0,423 & 0,679 \\
\hline 15 & 1,034 & 0,835 \\
\hline 20 & 0,816 & 0,179 \\
\hline 25 & 0,433 & 0,946 \\
\hline 30 & 0,580 & 0,413 \\
\hline
\end{tabular}

Tabel 1 Data Kehilangan Berat Poliuretan yang Diinkubasi dalam Lumpur Aktif dan Pseudomonas aeruginosa.

Dari hasil penentuan kehilangan berat menunjukkan bahwa semua polimer dapat terbiodegradasi, meskipun dengan laju degradasi yang berbeda. Bertambahnya waktu inkubasi, persen kehilangan berat poliuretan mengalami penurunan. Pada waktu inkubasi 5 hari, poliuretan mengalami kehilangan berat paling tinggi. 


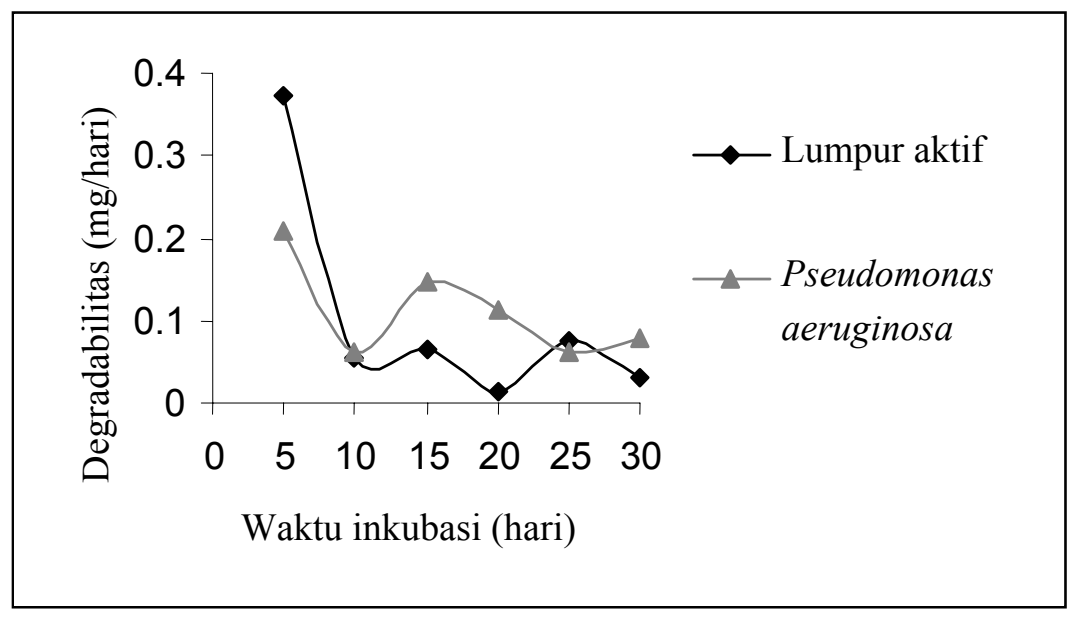

Gambar 2 Alur Degradabilitas Poliuretan terhadap Waktu Inkubasi.

Pada Gambar 2 nampak alur degradabilitas poliuretan terhadap waktu inkubasi. Dari gambar itu nampak bahwa untuk setiap variasi jenis mikroorganisme yang dipakai menunjukkan degradabilitas (laju kehilangan berat) produk poliuretan paling tinggi pada waktu inkubasi 5 hari, selanjutnya kurva mengalami penurunan dan peningkatan demikian seterusnya. Keadaan kurva yang turun naik setelah waktu inkubasi 5 hari, ini dapat disebabkan karena pada proses biodegradasi dilakukan penggantian media tiap 5 hari. Setelah penggantian media, maka mikroorganisme akan mendapatkan kembali keadaan yang kaya nutrisi dan dapat meningkatkan kembali aktivitasnya. Degradabilitas (laju kehilangan berat) semakin rendah dengan bertambahnya waktu inkubasi, ini menjadi petunjuk bahwa semakin lama waktu inkubasi aktivitas mikroorganisme dalam proses degradasi semakin rendah. Namun degradabilitas (laju kehilangan berat) totalnya semakin tinggi dengan bertambahnya waktu inkubasi, ini menjadi petunjuk bahwa semakin lama waktu inkubasi semakin banyak bagian polimer poliuretan yang terbiodegradasi oleh mikroorganisme pendegradasi.

Pada Gambar 3 nampak kurva difraktogram hasil analisis XRD poliuretan sebelum dan sesudah mengalami proses biodegradasi. Kedua kurva menunjukkan bentuk yang sama, namun kurva difraktogram poliuretan setelah proses biodegradasi menunjukkan penurunan intensitas daerah kristalin. Berdasarkan perhitungan derajat kristalinitas dengan cara membagi luas daerah kristalin dengan luas daerah seluruhnya (kristalin + amorf) diperoleh bahwa proses biodegradasi dapat menurunkan derajat kristalinitas poliuretan. Poliuretan sebelum didegradasi memiliki derajat kristalinitas sebesar 54,68\%, sedangkan setelah proses degradasi derajat kristalinitasnya menjadi $46,89 \%$. Keadaan tersebut dapat menjadi petunjuk bahwa akses mikroorganisme 
terhadap molekul polimer poliuretan menyebabkan berkurangnya kristalinitas atau keteraturan molekul poliuretan. Dengan demikian biodegradasi dapat mengakibatkan terjadi penambahan jumlah bagian amorf atau penurunan derajat kristalinitas molekul poliuretan.
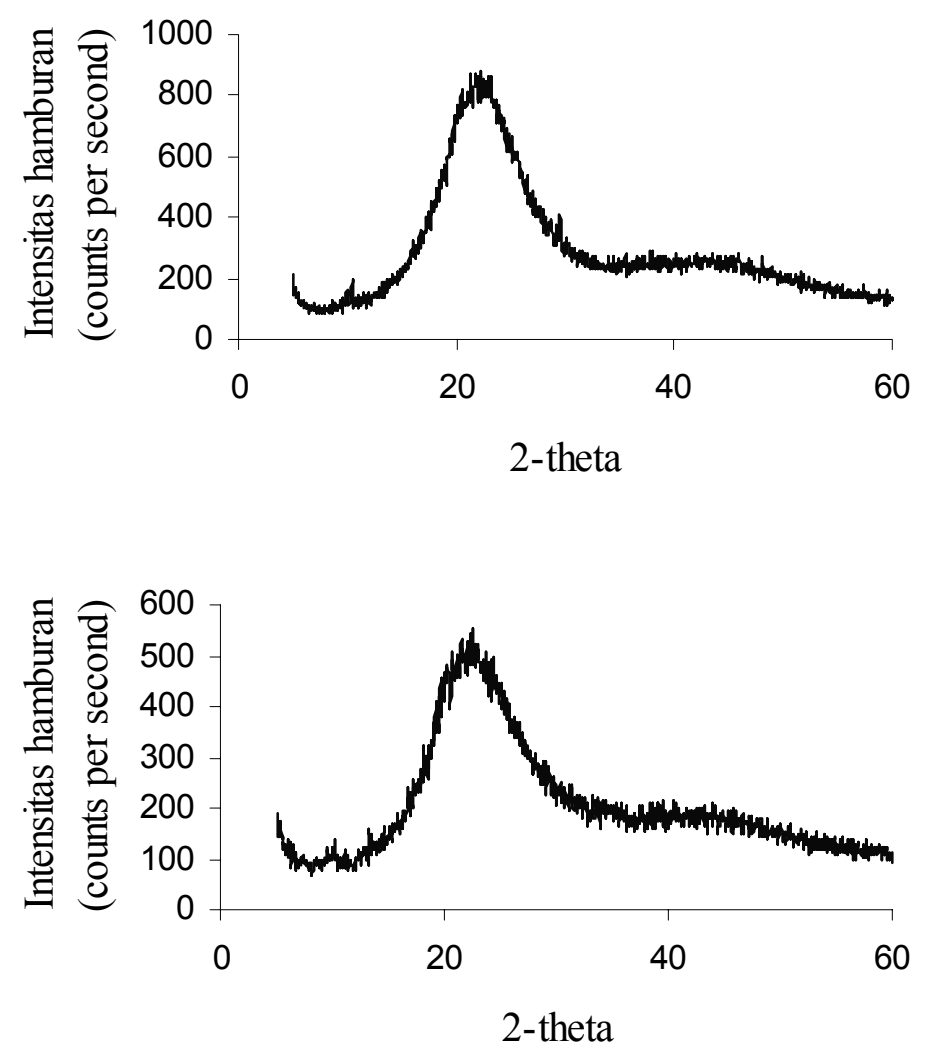

Gambar 3 Kurva Difraktogram XRD Poliuretan Sebelum (Atas) dan Sesudah (Bawah) Proses Degradasi dalam Lumpur Aktif.

Hasil analisis dengan teknik spektrofotometri FTIR menunjukkan bahwa poliuretan yang mengalami proses biodegradasi terjadi penghilangan puncak serapan pada daerah bilangan gelombang sekitar $1700-1720 \mathrm{~cm}^{-1}$ yang merupakan ciri khas untuk suatu poliuretan dalam hal ini gugus uretan NHCOO. Hilangnya puncak serapan gugus uretan menjadi petunjuk bahwa gugus fungsi tersebut merupakan sumber nutrisi bagi mikroorganisme.

Proses degradasi terhadap poliuretan hasil sintesis dari PEG400 dan MDI dengan lumpur aktif dalam media LB cair penggantian media tiap 5 hari 
menunjukkan lebih mudah terdegradasi dibandingkan dengan penelitian sebelumnya. Poliuretan hasil sintesis dari selulosa dengan MDI tanpa penambahan dan dengan penambahan polipropilen glikol lebih mudah mengalami pemutusan rantai utama dibandingkan dengan selulosa [5]. Poliuretan yang berasal dari lignoselulosa, PEG, dan MDI mengalami kemudahan degradasi di antara kayu beech dan kayu cryptomeria [6]. Poliuretan hasil sintesis dari poli-D,L-asam laktat, PEG400, dan pMDI menunjukkan kehilangan berat sangat rendah $(\sim 1 \%)[7]$.

\section{Kesimpulan}

Poliuretan dapat disintesis dari polietilen glikol 400 dan metilen-4,4'difenildiisosianat, yang ditunjukkan dengan munculnya puncak-puncak serapan karakteristik poliuretan.

Dari hasil penentuan kehilangan berat menunjukkan bahwa semua polimer poliuretan dapat terdegradasi, meskipun dengan laju degradasi yang berbeda. Proses biodegradasi poliuretan dalam media LB cair lebih efektif dengan lumpur aktif daripada dengan Pseudomonas aeruginosa.

\section{Daftar Pustaka}

1. Ramanathan, L. S., Sivaram, S. \& Munmaya, K. M., Polyurethane, http://www.oup-usa.org/pdh/PDH-815.PDF (2003).

2. Woods, G., The ICI Polyurethanes Book, ed.2, John Wiley \& Sons New, hal $1-6$ (1987).

3. Nicholson, J. W., The Chemistry of Polymer, ed.2, The Royal Society of Chemistry, hal 19, 71 (1997).

4. Ulrich, H., Introduction to Industrial Polymers, Hanser Publishers, hal 83-88 (1982).

5. Schnabel, W., Polymer Degradation, Principles and Practical Applications, Macmillan Publishing Co. Inc., hal 154 - 176 (1981).

6. Hatakeyama, H., Hirose, S., Hatakeyama, T., Nakamura, K., Kobashigawa, K. \& Morohoshi, N., Biodegradable Polyurethanes from Plant Component, J. Pure Applied Chemistry, A32(4), 743 - 750 (1995).

7. Albertsson, A. C. \& Huang, S. J. (ed), Biodegradation of Poly-D,L-Lactic Acid Polyurethanes, dalam Degradable Polymers, Recycling, and Plastics Waste Management, Marcel Dekker Inc., hal 81-85 (1995).

8. Huang, S. L., Structure-Tensile Properties of Polyurethanes, Eur. Polym. J., 10-12, 1563-1567 (1997).

9. Hartomo, A. J., Dasar-DasarProfesiPoliteknik Pemrosesan Polimer Praktis, ed.1, Penerbit Andi Offset Yogyakarta, hal 100 (1993). 